\title{
PALESTRA:
}

\section{Proposta curricular de música para o município de Florianópolis}

\author{
Sérgio L. F. Figueiredo
}

A promulgação da Nova Lei de Diretrizes e Bases da Educação Nacional (Lei 9394/96) em dezembro de 1996, deflagrou um movimento nacional referente aos currículos das várias áreas do conhecimento escolar. Os Parâmetros Curriculares Nacionais (PCNs) foram publicados em 1997 e 1998 com o intuito de promover uma base para as transformações desejadas para os currículos de Estados e Municípios.

A partir destes dois grandes documentos (LDB e PCNs), Estados e Municípios brasileiros vêm promovendo a elaboração de suas propostas curriculares. Neste processo, o Estado de Santa Catarina publicou em 1998 a versão definitiva de sua Proposta Curricular e a cidade de Florianópolis está na fase final para a publicação de seus referenciais curriculares.

A Secretaria Municipal de Educação de Florianópolis vem trabalhando com consultorias nas várias áreas de conhecimento escolar. Tais consultorias atuaram diretamente com os professores da rede municipal de ensino e com técnicos da secretaria de Educação, e hoje 
estão dirigidas também para a elaboração de documento por área, além da capacitação permanente de professores. Neste contexto, as Artes estão tratadas dentro de suas especificidades e há consultores para as áreas de Música, Teatro e Artes Plásticas.

Os pontos principais do documento de música foram definidos ao longo do processo de capacitação dos professores da rede municipal, onde se procedeu a leitura e síntese dos aspectos referentes à música nos documentos oficiais já publicados, como LDB, PCNs, Proposta Curricular do Estado de Santa Catarina, e outros.

A elaboração do documento está a cargo do consultor de música da prefeitura que é o autor deste texto. 0 documento elaborado está sendo discutido nas reuniões de capacitação de professores e a prefeitura deverá publicar uma versão definitiva dos documentos de todas as áreas ainda neste semestre.

Cabe destacar que o texto está dirigido para profissionais da educação, não só os profissionais da educação musical. Para a compreensão aprofundada das questões apresentadas no documento, é necessário que se proceda continuamente a capacitação de professores da rede municipal de ensino. Neste primeiro semestre de 2000 , estão participando dos processos de capacitação por área também os professores das séries iniciais. Desta forma se pretende ampliar as discussões sobre educação musical atingindo um número maior de 
profissionais da educação que atuam durante vários anos com as crianças das séries iniciais e que muitas vezes não têm formação musical para contribuir com o desenvolvimento musical das crianças nesta faixa etária. Por isso o documento não está dividido em educação infantil, ensino fundamental e médio, pois se pretende publicar um documento norteador para os profissionais da educação em geral. As questões metodológicas específicas por faixa etária, tipo de curso e de profissional, são assuntos para a capacitação permanente de professores.

A seguir, encontra-se 0 documento completo que foi apresentado à Secretaria Municipal de Educação de Florianópolis e o objetivo desta exposição é principalmente ouvir as críticas e opiniões dos educadores musicais participantes deste Encontro Regional Sul da ABEM com vistas ao aprimoramento deste documento para sua versão definitiva. 


\title{
Prefeitura municipal de Florianópolis Documento referente à elaboração de currículos
}

\author{
Área de música
}

Consultor: Sérgio Luiz Ferreira de Figueiredo

Dezembro, 1999.

\section{Introdução}

Desde o século passado a música está incluída na prática escolar com diferentes tendências e enfoques. Mas a prática da educação musical nunca esteve presente na totalidade dos sistemas de ensino por várias razões, como por exemplo, a falta de professores especializados ou a substituição da música por atividades consideradas mais 'úteis' no currículo escolar.

O movimento do Canto Orfeônico idealizado e desenvolvido por Villa-Lobos a partir da década de 1930, que pretendia unificar a educação musical no sistema educacional brasileiro, enfatizou uma prática centrada nas idéias de coletividade e civismo, condizentes com o Estado Novo. Os professores do movimento do Canto Orfeônico eram em grande parte originários do antigo conservatório e supervisionados pela Superintendência de Educação Musical e Arte do Distrito Federal (SEMA). 
O Canto Orfeônico foi substituído pela Educação Musical em 1961 pela LDB. Já neste período observa-se uma prática educacional em música influenciada por eminentes educadores musicais estrangeiros que, em seus países, desenvolvem e propagam uma educação musical diferente dos modelos tradicionais do ensino de música. Tal prática, embasada no firme propósito de proporcionar uma educação musical mais abrangente e para todos os indivíduos, apresenta uma oposição ao ensino da teoria musical e à ênfase nos aspectos matemáticos e notacionais da música. As influências de E. J. Dalcroze, Z. Kodály, C. Orff, e E. Willems, dentre outros, estão presentes em práticas de educadores musicais brasileiros que tiveram o privilégio de conhecer e estudar tais métodos. No entanto, sua aplicação restringe-se a pontos isolados do território nacional e o modelo 'conservatorial' permanece muito presente na prática da educação musical escolar.

A lei 5692/71 que instituiu a Educação Artística como prática polivalente trouxe sérias implicações para a prática pedagógica. Os cursos formadores dos profissionais da Educação Artística ofereciam a habilitação curta - dois anos de formação geral em todas as linguagens artísticas - e a habilitação plena - mais dois anos numa área artística escolhida. É inconcebível que um indivíduo detenha os conhecimentos específicos de cada linguagem artística em dois anos, e além disso esteja preparado pedagogicamente para ser professor de cada 
linguagem artística. E para completar este quadro, o ensino de todas as linguagens artísticas deve ocorrer no reduzido espaço destinado à Educação Artística no currículo escolar. São raros os exemplos positivos de aplicação da polivalência e a prática tem demonstrado a inconsistência desta proposição. Os professores de Educação Artística, em geral habilitados em uma área artística, optam pelo desenvolvimento desta área em sua prática pedagógica. Por razões diversas predominam os professores de Educação Artística com habilitação em Artes Plásticas, e muitos professores de música não se dirigiram para a educação artística na escola regular optando por outras atividades profissionais, também de ensino, em escolas livres ou escolas especializadas.

Há vários anos a maioria das universidades brasileiras formadoras dos profissionais em Educação Artística optaram por oferecer apenas as habilitações plenas por considerarem insuficiente a proposição da licenciatura curta em artes. São raras as escolas de nível superior que ainda insistem no oferecimento das licenciaturas curtas. Tais decisões, incorporadas lentamente no processo de reformulação curricular das universidades, não provocaram mudanças substanciais na legislação do ensino fundamental e médio. Parece que toda a discussão acumulada a respeito das especificidades não diz respeito à legislação que define e contrata os profissionais que irão atuar nas escolas, provocando um grande entrave para 
os egressos de cursos superiores de Educação Artística. Tais legislações não têm contribuído para o aprimoramento do ensino das artes na escola e predominam as idéias do senso comum que considera arte apenas como entretenimento e a formação artística é tida como irrelevante na educação dos indivíduos.

A nova LDB e os PCN trazem algumas possibilidades de reformulação deste quadro geral do ensino de artes no país. A partir da substituição do termo Educação Artística pelo Ensino de Artes, e pela ausência do termo polivalência, vislumbra-se um período diferente daquele que temos vivenciado em relação ao tratamento da arte nas escolas. Evidentemente só a troca de palavras não promove mudanças, mas é possível compreender que a supressão de certos termos desgastados com relação ao ensino das artes tem por finalidade estimular a busca por novas e mais eficientes estratégias com relação às atividades no campo das artes na escola. Este processo de reformulação curricular do município de Florianópolis engaja-se neste movimento nacional deflagrado pelas novas legislações e as artes estão tratadas individualmente, respeitando-se as especificidades de cada linguagem.

No entanto, ainda é preciso romper com muitas barreiras relacionadas à arte e seu ensino, tanto na comunidade em geral, como nos sistemas educacionais. Nunca se produziu tanto material bibliográfico nas diversas áreas artísticas como nos dias atuais. Tal bibliografia, 
infelizmente ainda inacessível para grande parte da população escolar, demonstra a importância da abordagem das diversas áreas artísticas como formas autônomas de conhecimento. As particularidades de cada linguagem podem e devem ser sistematicamente desenvolvidas no âmbito escolar, afim de reorganizar propostas e redimensionar o papel das artes no currículo e na vida educacional dos indivíduos.

\section{Referenciais teórico-metodológicos}

Para a elaboração do currículo de música estarão sendo respeitados os diferentes referenciais teórico-metodológicos disponíveis na área de educação musical, em sintonia com a proposta geral da Secretaria de Educação do Município de Florianópolis, que "optou por realizar esta ação numa perspectiva de tolerância política" (Alves, 1999, p.1). Está assegurada a liberdade de se trabalhar a partir das mais variadas vinculações epistemológicas, o que possibilita uma discussão ampla que inclui de fato os profissionais especialistas da área de música. Pretende-se "buscar definir preocupações comuns e explicitar aqueles elementos que aproximem diferentes perspectivas teóricas" (idem, p. 2).

Em termos da educação em geral, será necessária a tolerância política para que ocorra efetivamente o estabelecimento da educação musical como área de conhecimento pertencente ao currículo escolar. Música não 
pode ser tratada exclusivamente como uma aula onde se preparam festas da escola. Por mais que a atividade musical esteja diretamente relacionada ao entretenimento, a música na escola precisa assumir um papel relevante enquanto forma de conhecimento, e isto só será possível a partir da inclusão da disciplina e da sua continuidade nos ensinos fundamental $e$ médio. É preciso que se aprimorem as organizações curriculares e que cada linguagem artística tenha presença garantida de forma digna e real. Não basta o discurso da mudança de paradigma se ainda os professores das diferentes linguagens artísticas estão à margem do processo escolar, com número de aulas insuficientes, espaços inadequados, desprestígio enquanto mediadores de processos educacionais relevantes. Neste processo de elaboração de currículos é preciso estar garantida a presença e a continuidade da educação musical, e isto é uma questão de tolerância política básica. Música é uma forma de conhecimento e deve ser respeitada como tal.

Em termos específicos da educação musical, a tolerância política deverá ocorrer possibilitando a liberdade de trabalho de profissionais com as mais diversas formações musicais. É sabido que a formação musical na universidade é extremamente diversificada, configurando profissionais com diferentes abordagens. Desta forma pretende-se tratar com o devido respeito diferentes pontos de vista no desenvolvimento de conteúdos específicos. 
Diferentemente de outras áreas já estabelecidas no currículo escolar, a educação musical, que esteve quase ausente durante tanto tempo, estará se deparando com questões presentes na cultura escolar, onde ensinar música está diretamente vinculado a ensinar um instrumento musical, ou ainda, que só pode aprender música quem tem talento. Estes aspectos do senso comum, infelizmente também pertencem ao universo de professores de música que, aberta ou veladamente, estabelecem, através de suas metodologias, práticas discriminatórias. 0 empenho dos profissionais da educação musical terá que ser muito grande e a argumentação a respeito de diversos posicionamentos teórico-metodológicos deverá ser clara e firme no sentido de diferenciar práticas pedagógicas diversas, garantidas pela tolerância política, daquelas práticas pedagógicas discriminatórias que não deveriam conviver nesta proposta curricular.

Referenciais teórico-metodológicos estão disponibilizados na literatura brasileira através de publicações traduzidas de autores consagrados internacionalmente, assim como através da produção de autores brasileiros que publicam resultados de suas investigações educacionais em música. E. Willems, E. J. Dalcroze, C. Orff, Z. Kodály, H. Villa-Lobos, S. Suzuki, J. Paynter, M. Schafer, para citar os mais conhecidos e aplicados, apresentaram questões significativas para a educação musical e podem conviver na prática escolar. Mas é importante ressaltar que "não há receitas 
prontas, e não é a assinatura de um mestre 'consagrado' que irá garantir nossa prática cotidiana em sala de aula" (Penna, 1995, p.82). Estão disponibilizados na literatura musical, estudos sobre a aplicação destes métodos em diferentes contextos, comparação entre autores, críticas sobre as diversas abordagens, e todo este material deverá contribuir para uma aplicação consistente e fundamentada. Aqui também devem estar incluídas reflexões sobre os pressupostos filosóficos e psicológicos de cada método, além de cuidadosa avaliação do contexto onde se pretende desenvolver tais práticas.

Como apresenta M. Penna (1995), "precisamos, sim, de alternativas metodológicas, aliadas ao domínio de conteúdos" (p.82). 0 aprofundamento em diferentes metodologias deve ser fortemente recomendado para que se evite a superficialidade, os modismos, e o tradicional 'ecletismo' na educação musical. Muito comum na área de música, o ecletismo tem provocado uma incompreensão da própria natureza da educação musical em vários aspectos, principalmente porque não questiona posturas pedagógicas, recortando de cada método aquilo que é aparentemente mais fácil ou conveniente. É preciso muito critério para estabelecer conexões metodológicas e agir com segurança no estabelecimento de programas e atividades de ensino musical. 
Necessário se faz incentivar os profissionais da educação musical a aprofundarem seus conhecimentos nas recentes teorias da educação musical, ainda bastante distantes dos estudos curriculares no Brasil. A teoria espiral do desenvolvimento musical de $\mathrm{K}$. Swanwick (1988) é a mais difundida e também já existem estudos brasileiros sobre tal teoria. $\mathrm{Na}$ literatura especializada também é importante pesquisar a teoria proposta por M. L. Serafine (1988), que aborda música como cognição, música como uma modalidade de conhecimento distinta, e procura identificar os processos cognitivos relacionados ao pensamento musical. Ainda no campo da cognição são importantes os trabalhos de $\mathrm{H}$. Gardner (1983) relacionados às inteligências múltiplas, onde se inclui uma inteligência musical autônoma.

Ainda na busca de referenciais teóricometodológicos é de fundamental importância a contribuição da psicologia da música para a educação musical. Os trabalhos de Aiello (1994), Deutsche (1982), Hargreaves (1986), Oliveira (1996), Sloboda (1985), entre outros, acrescentam elementos imprescindíveis para o desenvolvimento de uma educação musical consistente, e todo educador musical deveria ter acesso a esta literatura, que sistematicamente tem sido discutida e apresentada nos congressos da área de educação musical. 
A sociologia da música também é uma área recente que muito tem contribuído para a reflexão e compreensão de conceitos em educação musical. Pesquisadores brasileiros, dentre eles, Arroyo (1994), Souza (1996) e Tourinho $(1993,1996)$, têm produzido material importante para os educadores musicais e a prática da música na escola, enfatizando questões contextuais.

Aspecto que merece extremo cuidado é o talento, com seus conceitos e discriminações na área do ensino musical. A literatura de educação musical também dispõe de um grande número de estudos e testes relacionados à medição de habilidades musicais, e muitas críticas acompanham tal literatura. Não é possível determinar com precisão qual é o grau de musicalidade de um indivíduo. 0 que se pode identificar são certas facilidades ou aptidões em certos indivíduos, o que não exclui a possibilidade de outros indivíduos 'menos aptos' desenvolverem habilidades musicais. Considerar o talento como ponto de partida ou como condição essencial para a aprendizagem musical é fomentar uma educação pela exclusão, é pretender sedimentar a educação musical num plano intangível.

Além das área já mencionadas como referencial para e educação musical, é possível encontrar também na literatura específica outras modalidades de estudos referentes à acústica, por exemplo, ou ainda relações entre música e matemática, música e linguagem, 
história da música e apreciação musical. Mas apenas um acervo teórico significativo não garante qualidade de ensino. Faz-se necessário estimular a prática da pesquisa em educação musical com 0 intuito de aprimorar continuadamente os processos de ensinoaprendizagem. A pesquisa pode representar o estabelecimento de práticas mais consistentes porque permite a verificação e análise de inúmeros aspectos relacionados à educação. Ainda não há tradição de pesquisa fora da universidade, mas cada professor pode desenvolver pesquisa a partir de sua própria prática nas escolas de primeiro e segundo graus. A capacitação permanente dos professores pode também se dar através da pesquisa, tornando cada indivíduo mais autônomo e mais consciente de sua atividade no contexto escolar.

\section{Democratização do acesso}

\section{e da gestão}

Parte-se do princípio que existe a possibilidade de uma educação musical para todos os indivíduos que freqüentam a escola, assim como se oferece uma educação matemática para todos os indivíduos que participam de um processo escolar.

A escola deve propiciar uma formação mais plena para todos os indivíduos. As mudanças de paradigmas deverão sair dos discursos para a prática efetivamente. Muito se fala da escola formadora do cidadão mais 
consciente de si e do seu mundo, mas ainda se reforça a racionalidade na escola, ignorando que a formação plena do indivíduo também passa pelo desenvolvimento dos aspectos emocionais e sensíveis. A música é uma forma de conhecimento que possibilita modos de percepção e expressão únicos e não pode ser substituída por outras formas de conhecimento.

A democratização do acesso também passa pela música como pertencente ao patrimônio cultural da humanidade, e portanto, pertencente a todos os indivíduos, sem distinção. Nesta linha de pensamento também a educação musical deve se conscientizar de seu papel na cultura escolar, contribuindo para a ampliação do universo sonoro do estudante, incorporando músicas de diferentes formas, épocas e propostas. As questões referentes à música popular, erudita, folclórica, internacional, atual, antiga, devem compor elementos fundamentais para uma efetiva democratização da música no contexto escolar.

Devemos considerar, ainda, como um aspecto importante para a democratização do acesso aos bens artístico-culturais, a manutenção da disciplina de música com carga horária compatível para uma aplicação consistente e significativa na escola, "de forma a promover o desenvolvimento cultural dos alunos" (LBD, Art. $26 \S 3^{\circ}$, apud Saviani, 1997, p.171).

A participação de professores e comunidade é fundamental para a democratização da gestão escolar. A elaboração de 
programas compatíveis com a realidade da escola, a não fixação de conteúdos e normas rígidas impostas de cima para baixo, são necessárias para a concretização de um projeto pedagógico honesto e adequado que observa, questiona, analisa e cresce com a pluralidade de opiniões a ações. Este espaço dos professores e da comunidade deve ser fortalecido e estimulado constantemente através de reuniões e eventos que garantam a continuidade de propostas, que avaliem constantemente os resultados e que promovam as mudanças necessárias para a manutenção de um educação com qualidade.

\section{Organização do Trabalho Didático}

A organização do trabalho didático apresenta-se como uma grande questão neste momento de reconstrução de currículos. Este projeto pedagógico, para sair do papel, só pode ser bem sucedido a partir da "construção de uma nova didática, que encarne as condições contemporâneas de existência da humanidade" (Alves, 1999, p.4). O conceito de escola está constantemente ameaçado pelas inovações tecnológicas, pelos meios de comunicação de massa, pela informática, e a comunidade escolar deve reivindicar o direito ao conhecimento. Em música não é possível conceber que o conhecimento pode se dar a partir de descrições de termos vagos de significado, ou de teorizações descontextualizadas, ou ainda através de fatos históricos ou 
anedóticos acerca de música e músicos. É preciso e é possível incluir música na educação básica. A qualidade e consistência desta atividade só serão possíveis a partir da reorganização da didática da educação musical desde a pré-escola até o segundo grau. A riqueza musical brasileira, da qual fazem parte todos os estudantes e toda a comunidade de Florianópolis, não pode ser ignorada na organização do trabalho didático no escola. Mas também a riqueza musical do mundo pode estar presente na educação musical. É preciso aparar muitos preconceitos e vencer muita resistência para que se possa construir de fato algo condizente com aquilo que se pode chamar de educação para o terceiro milênio. E a música não pode estar excluída desta discussão.

Especialistas deverão trabalhar conjuntamente, rediscutindo limites e vantagens de suas práticas isoladas, apresentando soluções pedagógicas para tantos desafios decorrentes de uma educação fragmentada que temos vivenciado. Os PCN, através dos Temas Transversais, podem servir como indicadores para estas discussões setoriais e gerais, com vistas a uma integração cada vez mais significativa dos conteúdos escolares.

A integração horizontal e vertical dos conteúdos se faz absolutamente necessária nesta proposta de elaboração de currículos. A educação musical pode estar perfeitamente integrada às atividades educacionais, conservando suas características e peculiari- 
dades. Integrar música às atividades educacionais não quer dizer cantar para decorar fórmulas matemáticas ou datas cívicas, ou ainda cantar para aprender elementos gramaticais de idiomas estrangeiros, mas, sim, incorporar efetivamente música como experiência educacional que permita aos indivíduos se relacionarem com esta forma de expressão humana. Para isso é necessário ampliar as discussões para além das especialidades de forma objetiva, enriquecendo a prática pedagógica de diversas áreas do conhecimento. É preciso buscar conhecer mais detalhadamente a realidade escolar, as características das diversas faixas etárias, as perspectivas culturais e educacionais associados aos conteúdos específicos de cada modalidade de conhecimento presente no currículo escolar. E a música faz parte da cultura, e não pode estar ausente nesta busca pela melhora da qualidade da educação do município.

\section{Objetivos}

Em linhas gerais, são objetivos da educação musical escolar:

- Incorporar a educação musical como parte integrante da formação do indivíduo, fortalecendo a idéia de que música faz parte da cultura e atinge direta ou indiretamente todos os indivíduos, contribuindo para o desenvolvimento da sensibilidade e possibilitando o aprimoramento do senso estético; 
- Propiciar ampla discussão sobre o papel da música na sociedade, resgatando conceitos estéticos de diferentes origens, incluindo música de diferentes povos, estilos, épocas, e tendências;

- Desenvolver sistematicamente conceitos e habilidades musicais através da criação, realização e apreciação de obras musicais através do estabelecimento de conteúdos significativos adequados à realidade escolar;

- Estimular a pesquisa musical nas diversas localidades escolares, estabelecendo vínculos com músicos locais e profissionais ligados à música, promovendo aproximações culturais, demonstrando perspectivas de mercado e produção musical, e estimulando a formação de novos profissionais;

- Prestigiar e freqüentar atividades musicais diversas, geradoras de vivências e questionamentos, compreendendo tais atividades de forma ampla, incluindo apresentações folclóricas, shows, concertos, recitais, palestras, vídeos, e outros.

\section{Conteúdos}

Os conteúdos estão apresentados genericamente com o intuito de possibilitar a reflexão por parte de quem vai construi-los e aplica-los. Não são receitas, mas pontos para serem considerados na elaboração de currículos em cada unidade escolar. Um grande avanço 
nesta nova legislação está na liberdade e flexibilidade com que se pode trabalhar o currículo. Não se pode confundir parâmetros com determinações. Parâmetros são referências para a elaboração curricular e não devem ser tomados como 'novos programas' a serem seguidos. Este é um novo aspecto desta legislação e é preciso estar atento para não se perder a oportunidade de construção de novas didáticas a partir do conhecimento, discernimento e entendimento daquilo que pode contribuir positivamente para a formação dos indivíduos na escola. Para que este processo ocorra satisfatoriamente é necessária a participação direta do professor, que não é simplesmente o executor de itens estabelecidos num programa definido a priori. O professor é co-autor do programa de curso, e elegerá conteúdos e estratégias para cumprir os objetivos que determinar.

Os conteúdos da educação musical nos diferentes níveis de escolaridade deveriam ser disponibilizados através de atividades de Criação, Execução e Apreciação. É recomendável que se estabeleça um equilíbrio entre estas atividades, proporcionando vivências que permitam reflexões e elaborações acerca de materiais musicais diversos, pré-existentes ou construídos pelos próprios alunos.

Os conteúdos poderão ser:

- percepção sonora

- timbre, altura, duração, intensidade, melodia, ritmo, forma, textura, outros 
- exploração de variados meios de produção sonora

- de sons ambientais até tecnologia sonora

- elementos de acústica básica

- propagação sonora, relações material-som, tamanho-som, outros

- exploração de diversos sistemas musicais

- modal, tonal, atonal, outros

- registros gráficos convencionais e nãoconvencionais

- sinais, códigos, símbolos, leitura, escrita

- habilidades motoras

- corporais, vocais, instrumentais

- execução, improvisação, recriação, arranjos

- elementos musicais diversos, músicas diversas

- apreciação significativa

- audição, comparação, discussão

- participação em apresentações que envolvam música

- música ao vivo, gravações, outras manifestações com música

- usos e funções da música no cotidiano

- música como lazer, entretenimento, profissão, devoção, terapia, outros

- pesquisa sobre música e músicos

- mercado de trabalho, produção musical, profissionais da música 
- música(s) da(s) cultura(s)

- classificação, análise, reflexão, posicionamento crítico

A metodologia, também individual, deve reconhecer possibilidades de trabalhos em grupos grandes, pequenos, ou ainda trabalhos individuais. Deve levar em conta que é possível construir instrumentos de trabalho, usar a voz, e outros recursos sonoros disponíveis ou disponibilizáveis (alunos podem trazer materiais). Paralelamente a esta ação de conseguir recursos na própria sala de aula, cada professor em sua unidade escolar deveria estar solicitando, com a devida argumentação, recursos materiais para o aprimoramento das atividades de educação musical. As atividades devem ser pensadas a partir de uma real situação associada à intenção de aprimoramento. Nesta proposta, onde o professor é co-autor do programa, não cabe mais a argumentação acerca da falta de recursos para se desenvolver uma educação musical de fato na escola regular. Através do estabelecimento criterioso de programas de educação musical em cada unidade escolar, construído a partir de sólidas fundamentações, poder-se-á oferecer uma educação de qualidade, que contribua para a formação de cidadãos melhor preparados para os desafios no novo milênio que se aproxima. 


\section{Referências Bibliográficas}

AIELLO, R. \& SLOBODA, J.A. (1994). Musical Perceptions. New York: Oxford University Press. ALVES, G. L. (1999). A elaboração de currículos para as escolas de educação infantil, de ensino fundamental e de educação de jovens e adultos: premissas. Florianópolis: Secretaria de Educação (mimeo).

ARROYO, M. (1990). Educação musical: Um processo de aculturação ou enculturação?. Em Pauta, 1. Porto Alegre: UFRGS.

BAMBERGER, J. (1991). The mind behind the musical ear. Cambridge: Harvard University Press.

BEYER, E. (1995). Os múltiplos desenvolvimentos cognitivo-musicais e sua influência sobre a educação musical. Revista da ABEM, 2. Associação Brasileira de Educação Musical.

Brasil. (1998). Parâmetros Curriculares nacionais ( $1^{a}$ a $4^{a}$ séries). Secretaria de Educação Fundamental. Brasília: MEC/SEF.

Brasil. (1998). Parâmetros Curriculares nacionais: Arte ( $5^{a}$ a $8^{a}$ séries). Secretaria de Educação Fundamental. Brasília: MEC/SEF.

Brasil. (1998). Referencial curricular nacional para a educação infantil. Secretaria de Educação Fundamental. Brasília: MEC/SEF. 
BUTLER, D. (1992). The musician's guide to perception and cognition. New York: Schirmer Books.

CHOKSY, L. (1981). The Kodaly context:

Creating and environment for musical learning. New Jersey: Prentice-Hall.

CHOKSY, L. (1988). The Kodaly method:

Comprehensive music education from infant to adult (2nd ed.). New Jersey: Prentice-Hall.

COLWELL, R. (1992). Handbook of Research on Music Teaching and Learning. New York: Schirmer Books.

DALCROZE, E. J. (1980). Rhythm, Music and Education, (4 $4^{\mathrm{a}}$ ed.). London: Hazell Watson e Viney.

DAVIES, S. (1994). Musical meaning and expression. New York: Cornell University Press. DEUTSCH, D. (1982). The Psychology of Music. San Diego: Academic Press.

Dourado, O. (1996). A formação do instrumentista. Fundamentos da Educação Musical, 3. Associação Brasileira de Educação Musical.

DRIVER, E. (1951). A pathway to Dalcroze eurhythmics. London: Thomas Nelson and Sons. ELLIOT, D. J. (1995). Music matters: A new philosophy of music education. New York: Oxford University Press. 
ELLIOT, J. E. (1990). El papel de la música y de la experiencia musical en la sociedad moderna: hacia uma filosofia global de la educación musical. In Gainza, V. H. (ed.) Nuevas Perspectivas de la Educacion Musical. Buenos Aires: Guadalupe.

FIGUEIREDO, S. L. F. (1996). O desafio da formação do professor de música. Florianópolis: Núcleo de Publicações CED - UFSC, Série Documentos, n. 01.

FIGUEIREDO, S. L. F. (1998). Currículos de música: Uma proposta da Universidade do Estado de Santa Catarina. Fundamentos da Educação Musical, 4. Associação Brasileira de Educação Musical.

FIGUEIREDO, S. L. F. (1999). Currículos de Música. Revista Arte Online, 1. Florianópolis: UDESC.

FISKE, H. E. (1996). Selected theories of music perception. Lewiston: The Edwin Mellen Press.

FLETCHER, P. (1989). Education and music. Oxford: Oxford University Press.

FUKS, R. (1991). O discurso do silêncio. Rio de Janeiro: Enelivros.

FUENTES, P. \& CERVERA, J. (1989). Pedagogia y Didática para músicos. Valencia: Piles.

GAINZA, V. H. (1964). La Iniciacion Musical del Niño. Buenos Aires: Ricordi.

GAINZA, V. H. (1977). Fundamentos, Materiales y Técnicas de la Educacion Musical. Buenos Aires: Ricordi. 
GAINZA, V. H. (1988). Estudos de psicopedagogia musical. São Paulo: Summus Editorial.

GAINZA, V. H. (ed.). (1990). Nuevas pespectivas de la educacion musical. Buenos Aires: Guadalupe.

GARDNER, H. (1983). Frames of mind: The theory of multiple intelligences. New York: Basic Books.

GARDNER, H. (1990). Art education and human development. Los Angeles: The Getty Education Institute for the Arts.

GERLING, F. (1989). Suzuki: o "método" e o "mito". Em Pauta, 1. Porto Alegre: UFRGS.

GRAETZER, G. \& YEPES, A. (1983). Guia para a Práctica de Música para Niños de Carl Orff. Buenos Aires: Ricordi.

GREEN, L. (1994). Pesquisa em sociologia da educação musical. (trad. Oscar Dourado). Revista da ABEM, 4.

HARGREAVES, D. J. (1986). The developmental psychology of music. Cambridge: Cambridge University Press.

HENTSCHKE, L. (1996). Um estudo longitudinal aplicando a Teoria Espiral de Desenvolvimento Musical de Swanwick com crianças brasileiras da faixa etária de 6 a 10 anos de idade: polo Porto Alegre, 1994. Música: pesquisa e conhecimento. Porto Alegre, Núcleo de Estudos Avançados, Curso de Pós Graduação em Música da UFRGS. 
HENTSCHKE, L. (1996). A teoria espiral de Swanwick como fundamentação para uma proposta curricular. Anais do $5^{\circ}$ Encontro Anual da $A B E M$ e $5^{\circ}$ Simpósio Paranaense de Educação Musical. Londrina: UEL.

LOPES, C. T. M. (1991). A pedagogia musical de Carl Orff. Em Pauta, 3. Porto Alegre: UFRGS.

Jorgensen, E. R. (1997). In search of music education. Urbana: University of Illinois Press.

KABALEVSKY, D. (1988). Music and education: A composer writes about musical education.

London: Jessica Kingley Publishers in association with UNESCO.

KOELLREUTTER, H. J. (1994). O humano: o objetivo de estudos musicais na escola moderna. Anais do $3^{\circ}$ Simpósio Paranaense de Educação Musical. Londrina: UEL.

LABUTA, J. A. \& Smith, D. A. (1997). Music education: Historical contexts and perspectives. New Jersey: Prentice-Hall.

MARTINS, R. (1985). Educação Musical:

Conceitos e preconceitos. Rio de Janeiro:

FUNARTE.

MARTINS, R. (1990). O valor educacional da arte. Porto Arte, 1. Porto Alegre: UFRGS.

MARTINS, R. (1994). Tradição e Inovação Musical: um Conflito Epistemológico. Anais do III Encontro Anual da ABEM. Salvador: EMUS. MEYER, L. B. (1994). Emotion and Meaning in Music. In: Aiello, R. \& Sloboda, J.A. Musical Perceptions. New York: Oxford University Press. 
MORENO, J. L. (1995). Psicologia de la musica e educacion musical. Madrid: Visor.

NOGUEIRA, I. (1997). O modelo da educação musical no brasil: Um drama em três atos incongruentes. Revista da ABEM, 4. Associação Brasileira de Educação Musical.

OLIVEIRA, A. (1993). Fundamentos da Educação Musical. Fundamentos da Educação Musical, 1. Associação Brasileira de Educação Musical.

OLIVEIRA, A. (1995). Currículo ALLI para o ensino da música na escola de $1^{\circ}$ grau. Anais do $4^{\circ}$ Simpósio Paranaense de Educação Musical. Londrina: UEL.

OLIVEIRA, A. (1996). A pesquisa em psicologia da música. Anais do $5^{\circ}$ Encontro Anual da ABEM e $5^{\circ}$ Simpósio Paranaense de Educação Musical. Londrina: UEL.

OLIVEIRA, J. (1994). A educação musical no Brasil: Primevos e postrídios. Anais do $3^{\circ}$ Simpósio Paranaense de Educação Musical. Londrina: UEL.

PAYNTER, J. (1991). Oir, aquí y ahora. Buenos Aires: Ricordi. Traduccion de J. Schultis.

PENNA, M. (1990). Reavaliações e Buscas em Musicalização. São Paulo: Loyola.

PENNA, M. (1995). Revendo Orff: Por uma reapropriação de suas contribuições. In Pimentel, L. G. (org.), Som, gesto, forma e cor: Dimensões da arte e seu ensino. Belo Horizonte: C/Arte. 
PENNA, M. (1995). Ensino de música: para além das fronteiras do conservatório. In Peregrino, $\mathrm{Y}$. R. (coord.), Da camiseta ao museu. João Pessoa: Editora Universitária UFPB.

PENNA, M. (org.). (1998). Os parâmetros curriculares nacionais e as concepções de arte. Grupo de Estudos do Departamento de Artes da UFPB. Paraíba: Centro de Ciências Humanas, Letras e Artes da UFPB.

PLUMMERIDGE, C. (1991). Music education in theory and practice. London: The Falmer Press.

REIMER, B. (1970). A philosophy of music education. New Jersey: Prentice-Hall.

Santa Catarina (1998). Proposta Curricular de Santa Catarina. Educação Infantil, Ensino Fundamental e Médio: Formação docente para educação infantil e séries iniciais. Florianópolis: COGEN.

SANTOS, R. M. S. (1991). Aprendizagem musical não-formal em grupos culturais diversos. Cadernos de Estudo - Educação Musical, 2/3. São Paulo: Atravez.

SANTOS, R. M. S. (1994). A natureza da aprendizagem musical e suas implicações curriculares - análise comparativa de quatro métodos. Fundamentos da Educação Musical, 2. Associação Brasileira de Educação Musical.

SANTOS, R. M. S. (1995). Crítica, Prazer e Criação Musical no Ensino-Aprendizagem Musical. Anais do $4^{\circ}$ Simpósio Paranaense de Educação Musical. Londrina: UEL. 
SAVIANI, D. (1997). A nova lei da educação:

Trajetória, limites e perspectivas (3. ed.). São Paulo: Autores Associados.

SCHAFER, M. (1991). O ouvido pensante. São Paulo: Editora da UNESP. Tradução de Marisa T. O. Fonterrada, Magda R. G. Silva e Maria Lúcia Pascoal.

SEASHORE, C. E. (1967). Psychology of music. New York: Dover Publications. (Original work published 1938)

SERAFINE, M. L. (1988). Music as cognition. New York: Columbia University Press.

SILVA, W. M. (1993). Zoltan Kodály - idéias e concepções sobre educação musical. Em Pauta, 8. Porto Alegre: UFRGS.

SLOBODA, J. A. (1985). The musical mind: The cognitive psychology of music. Oxford: Clarendon Press.

SOUZA, J. (1996). Contribuições teóricas e metodológicas da sociologia para a pesquisa em educação musical. Anais do $5^{\circ}$ Encontro Anual da ABEM e $5^{\circ}$ Simpósio Paranaense de Educação Musical. Londrina: UEL.

SOUZA, J. (1996). O cotidiano como perspectiva para a aula de música: concepção didática e exemplos práticos. Fundamentos da Educação Musical, 3. Associação Brasileira de Educação Musical.

SUZUKI, S. (1969). Nurtured by love. New York: Exposition Press. 
SWANWICK, K. (1979). A basis for music education. Berkshire: NFER-NELSON Publishing Company.

SWANWICK, K. (1988). Music, mind, and education. London: Routledge.

SWANWICK, K. (1994). Musical knowledge: Intuition, analysis and music. London: Routledge.

SZÖNYI, E. (1976). La Educacion Musical en Hungría através del Método Kodály. Budapest: Corvina.

TOURINHO, I. (1993). Música e controle: Necessidade e utilidade da música nos ambientes ritualísticos das instituições escolares. Em Pauta, 7. Porto Alegre: UFRGS. TOURINHO, I. (1993). Usos e funções da música na escola pública de $1^{\circ}$ grau. Fundamentos da Educação Musical, 1. Porto Alegre: UFRGS.

TOURINHO, I. (1993). Seleção de repertório para o ensino da música. Em Pauta, 8. Porto Alegre: UFRGS.

Tourinho, I. (1996). Práticas musicais de alunos de $3^{a}$ e $4^{a}$ séries: Implicações para o ensino de musica nas instituições educacionais. Anais do $5^{\circ}$ Encontro Anual da ABEM e $5^{\circ}$ Simpósio Paranaense de Educação Musical. Londrina: UEL. TRINDADE, B. P. (1998). Educação Musical com construção de instrumento: projeto realizado em uma turma de jovens de 08 a 14 anos de idade. Fundamentos da Educação Musical, 4. Associação Brasileira de Educação Musical. 
VILLA-LOBOS, H. (1976). Canto Orfeônico. São Paulo: Vitale.

VYGOTSKY, L. S. (1971). The psychology of art (Introd. A. N. Leontiev). Cambridge: The Massachusetts Institute of Technology.

WILLEMS, E. (1970). As Bases Psicológicas da Educação Musical. Suiça: Pró-Música.

WILLEMS, E. (1989). El Valor Humano de la Educacion Musical. México: Paidos.

ZAGONEL, B. (1991). Do gesto ao musical.

Cadernos de Estudo - Educação Musical, 2/3. 